\title{
Fauna edáfica em sistemas de produção de banana no Sul de Santa Catarina
}

\author{
Camila Elis Casaril ${ }^{1}$, Luís Carlos luñes de Oliveira Filho ${ }^{1}$, Julio Cesar Pires Santos ${ }^{1}$, Márcio Gonçalves da Rosa ${ }^{2}$ \\ 1 Universidade do Estado de Santa Catarina, Centro de Ciências Agroveterinárias, Lages, SC, Brasil. E-mail: camycasari|@gmail.com (ORCID: 0000-0003-1295-4971): \\ iunes1981@gmail.com (ORCID: 0000-0002-9010-481X); julio.santos@udesc.br (ORCID: 0000-0002-0414-9705) \\ 2 UCEFF Faculdades, Centro Politécnico, Unidade Chapecó, Chapecó, SC, Brasil. E-mail: marcio@uceff.edu.br (ORCID: 0000-0003-4886-5495)
}

RESUMO: A fauna do solo é sensível as modificações no ambiente e, portanto, pode ser eficiente como indicadora de qualidade em áreas de produção de banana. 0 objetivo do estudo foi avaliar os efeitos da produção de banana sobre a fauna edáfica em função das diferentes práticas culturais, manejos e aspectos químicos e físicos do solo. Avaliaram-se dois bananais e uma área de mata nativa, no sul de Santa Catarina em duas épocas. Para coleta de fauna utilizou-se o método de armadilhas de queda e o monólito de solo e ainda, avaliou-se a química e física do solo. Para fauna avaliou-se a abundância e riqueza de organismos amostrados, índices de diversidade de Shannon-Wiener e Pielou e procederam-se análises multivariadas. Os grupos de destaque na coleta por armadilhas de queda nos bananais foram Collembola, Formicidae e Acari e na coleta pelo monólito de solo, os grupos Oligochaeta e Diptera (larvas). Quanto aos índices de diversidade os bananais apresentam maiores índices na última coleta pelo monólito de solo. Identificou-se relação da fauna com $\mathrm{pH}, \mathrm{Al}^{+3}, \mathrm{Fe}^{+3}, \mathrm{Zn}^{+2}, \mathrm{Mg}^{+2}$, macroporosidade e densidade do solo. Conclui-se que as principais práticas culturais dos bananais relacionadas com a fauna são a calagem, adubação e disposição dos restos culturais no solo.

Palavras-chave: bananal; fauna do solo; práticas culturais

\section{Edaphic fauna in banana production systems in the South of Santa Catarina, Brazil}

ABSTRACT: Soil fauna is sensitive to changes in the environment and, therefore, can be efficient as an indicator of quality in banana production areas. The objective of the study was to evaluate the effects of banana on fauna and in function of the different cultural practices, management and chemical and physical aspects of the soil. Was evaluate two banana fields and an area of native forest, in the south of Santa Catarina in two seasons. For the collection of fauna, the technique of pitfall traps and soil monolith is used and also, a chemical and physical soil was evaluated. For the fauna was evaluated the abundance and richness of organisms sampled, diversity indexes of Shannon-Wiener and Pielou and multivariate processes was done. The main groups in the collection of pitfall traps in the banana fields were Collembola, Formicidae and Acari and in the collection by the soil monolith, are Oligochaeta and Diptera (larvae) groups. Regarding diversity indexes in banana plantations, the highest indices are in the last collection by soil monolith. Identified fauna relation with $\mathrm{pH}, \mathrm{Al}^{+3}, \mathrm{Fe}^{+3}, \mathrm{Zn}^{+2}, \mathrm{Mg}^{+}$, macroporosity and soil density. It is concluded, as the main cultural practices of the banana fields related with fauna are fertilization and disposal of cultural remains in the soil.

Key words: banana field; soil fauna; cultural practices 


\section{Introdução}

A bananeira (Musa sp.) é uma planta monocotiledônea, perene e originária dos trópicos úmidos do Sudeste Asiático. Atualmente o cultivo da banana é realizado em cerca de 120 países de regiões tropicais e subtropicais (Israeli \& Lahav, 2017).

O Brasil se destaca na produção de bananas por ser responsável por $6 \%$ da produção mundial e por $40 \%$ na América Latina, onde é o maior produtor (FAO, 2016). A região sul-brasileira corresponde a $10 \%$ da produção nacional sendo, Santa Catarina o maior produtor desta região com $60 \%$ da produção (IBGE, 2016).

O cultivo da banana envolve uma série de atividades que podem contribuir positivamente ou negativamente para a qualidade do solo. No que se refere aos efeitos negativos, temse na inserção da cultura a modificação das condições da física do solo como a densidade, estrutura e porosidade o que, afeta aeração, a disponibilidade de água, liberação de nutrientes, atividade microbiana, dentre outros fatores. Por outro lado, quando a cultura já está inserida, a acumulação de matéria orgânica advinda dos restos vegetais da pós-colheita pode garantir efeitos positivos à conservação da umidade do solo, sobre atividade biológica, no processo de decomposição da matéria orgânica, ciclagem de nutrientes e benefícios à física do solo. Outras atividades a serem consideradas no manejo dos bananais, com efeitos positivos sobre a cultura, são o controle de plantas invasoras, adubação, calagem, controle de pragas, escoramento das bananeiras, ensacamento de cacho e colheita (Arcoverde et al., 2015; Alves et al., 2004; Lichtemberg \& Lichtemberg, 2011; Santana et al., 2017).

As alterações causadas a partir das práticas de manejo e uso do solo tem efeito sobre a fauna edáfica, neste aspecto ela pode ser considera como indicadora de qualidade do ambiente edáfico. A fauna responde ao stress de ordem química, física ou biológica resultante das práticas de manejo e cultivo, através de alterações nas populações de um determinado ecossistema, portanto, a maneira como uma cultura é conduzida através do preparo do solo e uso de insumos é uma fonte de degradação do ambiente e da biologia do solo incluindo a fauna edáfica (Baretta et al., 2011; Balin et al., 2017).

A fauna do solo de acordo com o tamanho corporal pode ser classificada em mesofauna, organismos entre 0,2 e $2 \mathrm{~mm}$ e, macrofauna, organismos maiores de $2 \mathrm{~mm}$ (Melo et al., 2009). A mesofauna está envolvida em processos como a ciclagem de nutrientes, regulação da biomassa microbiana e representa ainda, uma fonte alimentar para outros organismos (Oliveira Filho et al., 2015). Já a macrofauna tem função importante no crescimento vegetal, pois, contribui para a manutenção da matéria orgânica e influencia na estruturação do solo através da melhoria das propriedades físicas do solo (Pompeo et al., 2016). A macrofauna também participa de diversos níveis tróficos dentro da cadeia alimentar, resultando em interações ecológicas complexas entre a fauna edáfica e as propriedades do solo (Baretta et al., 2010).
No que se refere à fauna edáfica em locais de produção de banana, as informações ainda são raras, tornando o tema relevante para a ciência e biologia do solo. Embora alguns trabalhos tenham sido conduzidos em locais de produção de banana, estes apenas abordam avaliações pontuais de áreas de bananal ou em consórcio com outras culturas, pouco explorando o potencial da fauna do solo nestes locais.

Diante deste contexto do apresentado, a hipótese do estudo é que as diferentes práticas culturais e manejos dos bananais estudados têm influência sobre a fauna do solo. Assim, o objetivo do presente estudo foi avaliar os efeitos da produção de banana sobre a fauna edáfica em função das diferentes práticas culturais, manejos e aspectos químicos e físicos do solo.

\section{Material e Métodos}

\section{Local de estudo}

O estudo foi realizado no município de Santa Rosa do Sul, no extremo sul de Santa Catarina. O clima da região, segundo a classificação Köppen, é o subtropical úmido (Cfa), apresentando verões quentes sem estação seca, com temperatura média anual entre 16 e $18{ }^{\circ} \mathrm{C}$, com chuvas variando de 1.400 a $1.600 \mathrm{~mm}^{2} \mathrm{ano}^{-1}$.

As áreas de estudo corresponderam a dois bananais (bananal 1 e bananal 2), distantes cerca de $3 \mathrm{~km}$ entre si, com diferentes práticas culturais e manejo, sendo o bananal 1 (B1) apresentou historicamente práticas de manejo e entrada de insumos externos em menor escala, quando comparado ao bananal 2 (B2) (Tabela 1) além disso, optou-se por incluir na avaliação um fragmento de mata nativa (MN) como área de referência.

A área de $M N$ trata-se de um fragmento sem intervenção antrópica ou entrada de animais, com tamanho aproximado de 1,5 ha, situada junto a uma área de produção de banana orgânica, distante aproximadamente $9 \mathrm{~km}$ do B1 e $6 \mathrm{~km}$ do B2. A vegetação encontrada na $\mathrm{MN}$ pertence à Floresta Ombrófila Densa Submontana do bioma Mata Atlântica (Estado de Santa Catarina, 2015; Vibrans et al., 2015). As coletas nas áreas de estudo foram realizadas em dezembro de 2015 e abril de 2016 para avaliar os efeitos das possíveis modificações no ambiente nesse período e o seu efeito sobre a fauna edáfica.

\section{Amostragem da fauna do solo}

As amostragens de fauna do solo foram realizadas através de dois métodos de coleta, visando melhor amplitude amostral da fauna edáfica (meso e macrofauna), em grade amostral de 12 pontos sendo, os pontos espaçados $10 \mathrm{~m}$ entre si e $10 \mathrm{~m}$ da borda do grid amostral, totalizando $2.100 \mathrm{~m}^{2}$ de área amostral em cada área estudada (Figura 1).

O primeiro método utilizado de coleta de fauna utilizado foi o de armadilhas de queda (Pitfall Traps) composta por frascos de vidro com dimensões de aproximadamente 15 $\mathrm{cm}$ de profundidade e $10 \mathrm{~cm}$ de diâmetro, contendo, 200 $\mathrm{mL}$ de solução detergente (concentração $0,5 \% \mathrm{v} / \mathrm{v}$ ), as armadilhas foram instaladas escavando o solo com auxílio 
Tabela 1. Características dos bananais estudados.

\begin{tabular}{|c|c|c|}
\hline Características & Bananal 1 & Bananal 2 \\
\hline Idade & 10 anos & 23 anos \\
\hline Uso anterior da área & Plantio de milho, aipim e fumo & $\begin{array}{l}\text { Plantio de banana da variedade Nanicão } \\
\text { (renovação do bananal para variedade atual } \\
\text { há } 12 \text { anos) }\end{array}$ \\
\hline Área produtiva & 10 ha & 24 ha \\
\hline Variedade & Prata Catarina & Prata Catarina \\
\hline Produtividade & 5 t ha-1 $^{-1}$ & 24 t ha-1 $^{-1}$ \\
\hline Calagem & Realizada há 10 anos & Realizada há 5 anos \\
\hline Práticas Culturais & $\begin{array}{l}\text { - Cachos não ensacados } \\
\text { - Desfolha a cada } 60 \text { dias } \\
\text { - Retirada da inflorescência masculina } \\
\text { - Colheita a cada } 30 \text { dias } \\
\text { - Não há retirada da última penca } \\
\text { - Há desbaste: mantidas as plantas mãe e filha } \\
\text { - Não há retirada dos resíduos próximos das } \\
\text { plantas }\end{array}$ & $\begin{array}{l}\text { - Cachos ensacados } \\
\text { - Desfolha a cada } 60 \text { dias } \\
\text { - Retirada da inflorescência masculina } \\
\text { - Colheita a cada } 15 \text { dias } \\
\text { - Há retirada da última penca } \\
\text { - Há desbaste: mantidas plantas mãe, filha e } \\
\text { neta } \\
\text { - Retirada dos resíduos próximos das plantas } \\
\text { (para controle de pragas) }\end{array}$ \\
\hline $\begin{array}{l}\text { Resíduos da colheita, desfolha e } \\
\text { desbaste }\end{array}$ & $\begin{array}{l}\text { Dispostos no bananal sendo parcialmente } \\
\text { picados e não espalhados }\end{array}$ & Dispostos no bananal após serem picados \\
\hline Entrada de animais ou máquinas & Não & Não \\
\hline Uso de herbicida (i.a. ${ }^{1}$ ) & Glifosato & $\begin{array}{l}\text { Herbicidas de contato: Dicloreto de Paraquate } \\
\text { e Glifosato }\end{array}$ \\
\hline Uso de inseticida (i.a.) & Não & $\begin{array}{l}\text { Imidacloprido + Beta-ciflutrina e imidacloprido } \\
\text { no ensacamento }\end{array}$ \\
\hline Uso de fungicida (i.a.) & $\begin{array}{l}\text { Óleo mineral e Propiconazole diretamente na } \\
\text { folha duas vezes ao ano }\end{array}$ & $\begin{array}{l}\text { Propiconazole, Tiofanato-Metílico e } \\
\text { Trifloxistrobina+ Tebuconazol diretamente na } \\
\text { folha e Mancozebe no cacho }\end{array}$ \\
\hline
\end{tabular}

${ }^{1}$ Ingrediente ativo.

$70 \mathrm{~m}$

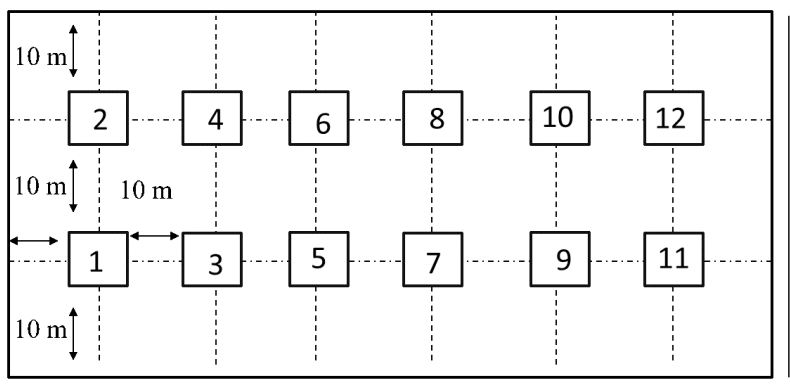

Área: $2.100 \mathrm{~m}^{2}$

Figura 1. Esquema do grid amostral utilizado nas áreas de estudo.

de um trado holandês, e posteriormente inserindo o frasco de vidro no local perfurado. As armadilhas permaneceram a campo por 72 horas e posteriormente foram recolhidas e levadas ao laboratório para separação manual, vertendo-se o líquido dos frascos sobre peneiras de malhas 2 e $0,10 \mathrm{~mm}$, os organismos encontrados foram fixados em álcool etílico $96 \%$ e acondicionados em frascos para posterior identificação (método adaptado de Baretta et al., 2014).

O segundo método de coleta de fauna utilizado consistiu na retirada de monólitos de solo com dimensões de $25 \times 25$ $\mathrm{cm}$ de largura e $10 \mathrm{~cm}$ de profundidade, conforme descrito por Anderson \& Ingram (1993) no Tropical Soil Biology and Fertility Method (TSBF), com catação manual. Os monólitos coletados, foram destorroados no campo e todos os organismos encontrados foram acondicionados em frascos plásticos contendo álcool etílico $96 \%$ para fixação e posterior identificação.

Após a triagem de fauna em cada método de coleta, foi realizada a identificação dos organismos no maior nível taxonômico possível (Classe/Subclasse/Ordem/Família/ Epifamília), com auxílio de um microscópio estereoscópico (Ruggiero et al., 2015). Posteriormente, foram determinados a abundância (indivíduos por armadilha, ind. arm. ${ }^{-1}$ ), densidade (indivíduos por metro quadrado, ind. $\mathrm{m}^{-2}$ ) e riqueza. Os índices de diversidade Shannon-Wiener $\left(H^{\prime}\right)$ e equitabilidade de Pielou ( $\left.J^{\prime}\right)$ foram determinados através da biblioteca VEGAN do programa estatístico $R$.

\section{Amostragem e análises químicas e físicas do solo}

Próximo de cada ponto de coleta da fauna, também se coletaram amostras de solo para a avaliação dos aspectos químicos e físicos. Avaliaram-se $\circ \mathrm{pH}$ em $\mathrm{H}_{2} \mathrm{O}, \mathrm{Ca}^{+2}, \mathrm{Mg}^{+2}$, $\mathrm{Al}^{+3}, \mathrm{H}+\mathrm{Al}, \mathrm{P}, \mathrm{K}^{+}, \mathrm{Cu}^{+2}, \mathrm{Zn}^{+2}, \mathrm{Fe}^{+3}, \mathrm{Mn}^{+2}$, capacidade de troca catiônica (CTC), carbono orgânico total (CO) e argila através de amostras de solo compostas coletadas na profundidade de 0-10 cm (Tedesco et al. 1995) e, ainda, densidade do 
solo (DS), porosidade total (PT), macroporosidade (Macro), microporosidade (Micro) do solo e bioporos (Bio) com anéis volumétricos na camada de 0-5 cm (Embrapa, 1997).

\section{Análise estatística}

A abundância (armadilhas de queda) e densidade (monólito de solo) foram submetidos à análise de variância (ANOVA One-way) e as médias comparadas pelo teste LSD ( $p$ $\leq 0,05)$ por meio do programa estatístico SPSS.

Além disso, realizou-se a análise multivariada dos dados, primeiramente executando a análise de correspondência retificada (Detrended Correspondence Analysis - DCA) com objetivo de avaliar o comprimento de gradiente sendo que, quando o gradiente foi menor ou igual a 3 (resposta linear) realizou-se análise de componentes principais (Principal Component Analysis - PCA). As variáveis ambientais explicativas (VAE) foram definidas por análise de redundância (Redundancy Analysis - RDA) sendo selecionadas através da identificação e remoção das variáveis colineares, por meio do fator de inflação (Variance Inflation Factor - VIF) e por operações de forward selection, usando sucessivas RDAs com base em permutações por teste de Monte-Carlo. O objetivo da RDA consistiu em selecionar um conjunto de variáveis químicas e físicas do solo (VAE) que possam ter influência sobre os grupos da fauna edáfica presentes nas áreas de estudo. Desse modo, foram mantidas apenas as VAE que melhor explicam a variação dos dados de fauna edáfica (significativas e não colineares), mantendo a significância da análise de $p \leq 0,05$. Toda a análise multivariada dos dados (DCA, RDA e PCA) foi realizada através do software estatístico CANOCO versão 4.

As VAE selecionadas foram submetidas à análise de variância (ANOVA One-way) utilizando o software estatístico SPSS sendo que, quando necessário os dados foram transformados através do software estatístico Action Stat Pro para obter-se a normalidade dos dados e homogeneidade das variâncias. O objetivo da análise de variância foi verificar as diferenças significativas entre os tratamentos $(p \leq 0,05)$ por meio do teste de Tukey.

\section{Resultados e Discussão}

No total foram amostrados pelo método das armadilhas de queda na coleta de dezembro de 2015, 3.116 organismos divididos em 13 grupos taxonômicos. Nesta coleta as áreas que apresentaram maiores médias de riqueza e abundância foram a MN seguida de B2. Já na coleta de abril de 2016 foram amostrados 954 indivíduos distribuídos em 9 grupos taxonômicos, sem diferenças significativas entre as áreas, para abundância e riqueza média (Tabela 2).

Os grupos mais representativos na coleta por armadilhas de queda (considerando aqueles que corresponderam a mais de $10 \%$ do total de indivíduos amostrados) para a coleta de dezembro na MN foram Coleoptera (54\%) e Collembola (15\%). Na coleta de abril nesta área, destacaram-se os grupos Coleoptera (16\%) e Formicidae (55\%). Nos bananais os grupos

Tabela 2. Média dos grupos taxonômicos da fauna edáfica por armadilhas de queda (ind. arm. ${ }^{-1}$ ) e monólito de solo (ind. $\mathrm{m}^{-2}$ ), índices de diversidade de Shannon-Wiener $\left(H^{\prime}\right)$ e equitabilidade de Pielou ( $J^{\prime}$ ) e riqueza nas áreas de produção de banana (B1 e B2) e na mata nativa (MN).

\begin{tabular}{|c|c|c|c|c|c|c|c|c|c|c|c|c|}
\hline \multirow{3}{*}{$\begin{array}{c}\text { Grupos } \\
\text { taxonômicos }\end{array}$} & \multicolumn{6}{|c|}{ Dezembro 2015} & \multicolumn{6}{|c|}{ Abril 2016} \\
\hline & \multicolumn{3}{|c|}{ Armadilhas de queda } & \multicolumn{3}{|c|}{ Monólito de solo } & \multicolumn{3}{|c|}{ Armadilhas de queda } & \multicolumn{3}{|c|}{ Monólito de solo } \\
\hline & $\mathrm{MN}$ & B1 & B2 & $\mathrm{MN}$ & B1 & B2 & $\mathrm{MN}$ & B1 & B2 & $\mathrm{MN}$ & B1 & B2 \\
\hline Acari ${ }^{1}$ & 8 & 3 & 14 & 0 & 0 & 0 & 1 & 3 & 5 & 0 & 0 & 0 \\
\hline Amphipoda & 5 & 0 & 0 & 23 & 1 & 0 & 0 & 0 & 0 & 7 & 15 & 0 \\
\hline Araneae & 1 & 1 & 2 & 4 & 1 & 4 & 1 & 1 & 1 & 1 & 4 & 0 \\
\hline Blattaria & 0 & 0 & 0 & 1 & 0 & 1 & 0 & 0 & 1 & 0 & 0 & 0 \\
\hline Chilopoda & 0 & 0 & 0 & 0 & 5 & 13 & 0 & 0 & 0 & 1 & 1 & 8 \\
\hline Coleoptera & 70 & 0 & 2 & 9 & 23 & 0 & 3 & 0 & 0 & 9 & 23 & 0 \\
\hline Collembola & 20 & 8 & 59 & 0 & 0 & 0 & 1 & 3 & 12 & 0 & 0 & 0 \\
\hline Diplura & 0 & 0 & 0 & 0 & 0 & 0 & 0 & 0 & 0 & 0 & 0 & 3 \\
\hline Diplopoda & 0 & 1 & 0 & 4 & 20 & 4 & 0 & 0 & 0 & 0 & 9 & 3 \\
\hline Diptera (larvas) & 7 & 1 & 3 & 4 & 13 & 0 & 2 & 0 & 0 & 0 & 55 & 29 \\
\hline Dermaptera & 0 & 0 & 0 & 3 & 0 & 11 & 0 & 0 & 0 & 0 & 0 & 0 \\
\hline Gastropoda & 0 & 0 & 0 & 4 & 5 & 0 & 0 & 0 & 0 & 0 & 1 & 1 \\
\hline Formicidae & 12 & 12 & 19 & 4 & 49 & 23 & 10 & 19 & 15 & 25 & 35 & 0 \\
\hline Hemiptera & 3 & 1 & 3 & 1 & 0 & 0 & 0 & 0 & 0 & 0 & 0 & 0 \\
\hline Hirudinea & 0 & 0 & 0 & 3 & 0 & 1 & 0 & 0 & 0 & 1 & 1 & 1 \\
\hline Isopoda & 4 & 0 & 1 & 53 & 8 & 0 & 1 & 1 & 0 & 21 & 17 & 3 \\
\hline Termitoidae & 0 & 0 & 0 & 0 & 13 & 0 & 0 & 0 & 0 & 0 & 0 & 0 \\
\hline Orthoptera & 0 & 0 & 0 & 4 & 0 & 0 & 0 & 0 & 0 & 0 & 1 & 0 \\
\hline Oligochaeta & 0 & 0 & 0 & 392 & 76 & 179 & 0 & 0 & 0 & 241 & 57 & 105 \\
\hline Opiliones & 0 & 0 & 0 & 3 & 0 & 0 & 0 & 0 & 0 & 0 & 0 & 0 \\
\hline $\begin{array}{l}\text { Total de } \\
\text { organismos } \\
\text { amostrados }\end{array}$ & 1.557 & 328 & 1.231 & 384 & 162 & 177 & 217 & 324 & 413 & 231 & 165 & 115 \\
\hline $\begin{array}{l}\text { Média } \\
\text { de organismos }\end{array}$ & $130 \pm 52,5 a^{*}$ & $28 \pm 25,6 b$ & $103 \pm 51,2 a$ & $32 \pm 10,6 a$ & $13 \pm 10,7 b$ & $15 \pm 9,5 b$ & $18 \pm 9,1 \mathrm{a}$ & $27 \pm 12,5$ a & $34 \pm 7,2 \mathrm{a}$ & $19 \pm 11,9 a$ & $14 \pm 10 a b$ & $10 \pm 9,6 b$ \\
\hline Riqueza total & 13 & 11 & 12 & 15 & 11 & 8 & 9 & 9 & 7 & 8 & 12 & 8 \\
\hline Riqueza média & $9 \pm 1,2 a$ & $5 \pm 2,7 c$ & $7 \pm 1 b$ & $5 \pm 1,3 a$ & $4 \pm 1,4 \mathrm{ab}$ & $3 \pm 1,4 b$ & $5 \pm 2,1 \mathrm{a}$ & $4 \pm 1,7 a$ & $4 \pm 1,1 \mathrm{a}$ & $3 \pm 1,9 a b$ & $4 \pm 1,9 a$ & $2 \pm 1 b$ \\
\hline $\mathrm{H}^{\prime}$ & 1,5 & 1,7 & 1,3 & 1,0 & 1,9 & 0,9 & 1,5 & 1,0 & 1,3 & 0,8 & 1,9 & 1,0 \\
\hline $\mathrm{J}^{\prime}$ & 0,5 & 0,5 & 0,4 & 0,3 & 0,6 & 0,3 & 0,5 & 0,3 & 0,4 & 0,3 & 0,6 & 0,3 \\
\hline
\end{tabular}

${ }^{1}$ Essa denominação inclui a Super Ordem Acariformes e Parasitiformes. *Letras iguais na linha para uma mesma época e método de amostragem representam tratamentos que não apresentam diferenças significativas pelo teste de Tukey $(p<0,05) . M N=$ mata nativa, $B 1=$ bananal $1, B 2=$ bananal 2 . 
Collembola, Formicidae e Acari se destacaram na abundância média nas duas épocas.

Para o método do monólito de solo foram amostrados na primeira coleta 723 indivíduos de 15 grupos diferentes na primeira coleta e na segunda, 511 indivíduos de 12 diferentes grupos. Quanto a densidade e riqueza média em dezembro, B1 obteve os menores valores já em abril, foi B2 que apresentou a menor densidade e riqueza média (Tabela 2).

Avaliando os grupos amostrados pelo monólito de solo e, considerando aqueles que representam mais de $10 \%$ do total de organismos, o grupo Oligochaeta mostrou-se representativo nas três áreas nas duas épocas de coleta (MN: dezembro $=76 \%$, abril $=78 \%$; B1: dezembro $=35 \%$, abril $=$ 26\%; B2: dezembro $=76 \%$, abril $=69 \%$ ). Destacaram-se ainda os grupos Coleoptera e Formicidae no B1 nas duas épocas de coleta e Diptera (larvas) no B1 e B2 na segunda coleta.

Com relação ao número de indivíduos amostrados para os dois métodos de coleta (armadilhas de queda e monólito de solo), nota-se que independe do método utilizado, na coleta de dezembro de 2015 foi amostrado maior número de organismos do que em abril de 2016. Este fato pode estar relacionado com a maior precipitação regional em dezembro já que, as variações sazonais de temperatura do ar e pluviosidade têm efeito na temperatura e umidade do solo, afetando na abundância de organismos edáficos (Oliveira Filho et al., 2014). Nesse sentido, a precipitação regional do local onde se realizaram as coletas foi de $211 \mathrm{~mm}$ no mês de dezembro de 2015 enquanto que em abril de 2016, essa precipitação foi de 113 mmm (INMET, 2016).

Com relação aos índices de diversidade de ShannonWiener $\left(\mathrm{H}^{\prime}\right)$ e equitabilidade de Pielou $\left(\mathrm{J}^{\prime}\right)$ conforme se verifica na Tabela 2, o B1 apresenta maiores valores de $\mathrm{H}^{\prime}$ e J' do que B2 nas avaliações de dezembro, independentemente do método de coleta e, na avaliação pelo método do monólito de solo em abril. Estes maiores índices de diversidade podem ser resultado do manejo das áreas de produção de banana que consequentemente, afetam a distribuição da abundância de organismos dentro dos diferentes grupos taxonômicos.

Os índices de diversidade dependem da distribuição da abundância de indivíduos dentro dos grupos ou espécies (Aquino \& Correia, 2005). Assim, a concentração da abundância em apenas alguns grupos, pode resultar em menores índices de diversidade em função da menor distribuição da abundância entre os grupos taxonômicos. Nesse aspecto, B2 pode ter menores índices que B1 já que, na coleta de dezembro por armadilhas de queda o grupo Collembola dominou a abundância média de organismos amostrados nesta área. Já nas coletas pelo monólito de solo em dezembro e abril, as maiores médias de organismos amostrados em B2 são do grupo Oligochaeta. A atividade do manejo em B2 que pode ter influenciado a concentração das abundâncias em torno dos grupos Collembola e Oligochaeta, é a aplicação de cama de aviário, a qual não ocorre em B1.

A dominância do grupo Collembola em uma área de consórcio de café e banana foi associada com o ambiente edáfico que provia proteção e alimento a fauna. Nesse sistema, havia aplicação de cama de aviário e ainda, um composto contendo resíduos de bananeira (Guimarrães et al., 2015). No presente estudo, B2 recebe além de cama de aviário, os restos culturais das bananeiras.

No que se trata de Oligochaeta os resultados referentes a alta abundância do grupo em uma área de campo nativo foram associados a oferta de recursos alimentares para o grupo, advinda da deposição de restos vegetais (palha) e aplicação de esterco de gado (Pompeo et al., 2016). No caso da produção de banana, a cama de aviário aplicada em B2 pode representar uma fonte energética extra para fauna, além dos restos culturais, justificando a maior abundância de Oligochaeta nessa área quando comparada a B1.

Na Figura 2 estão representadas as análises multivariada de PCA (Figura 2A) e RDA (Figura 2B) para as armadilhas de queda em dezembro de 2015 onde, verifica-se a separação
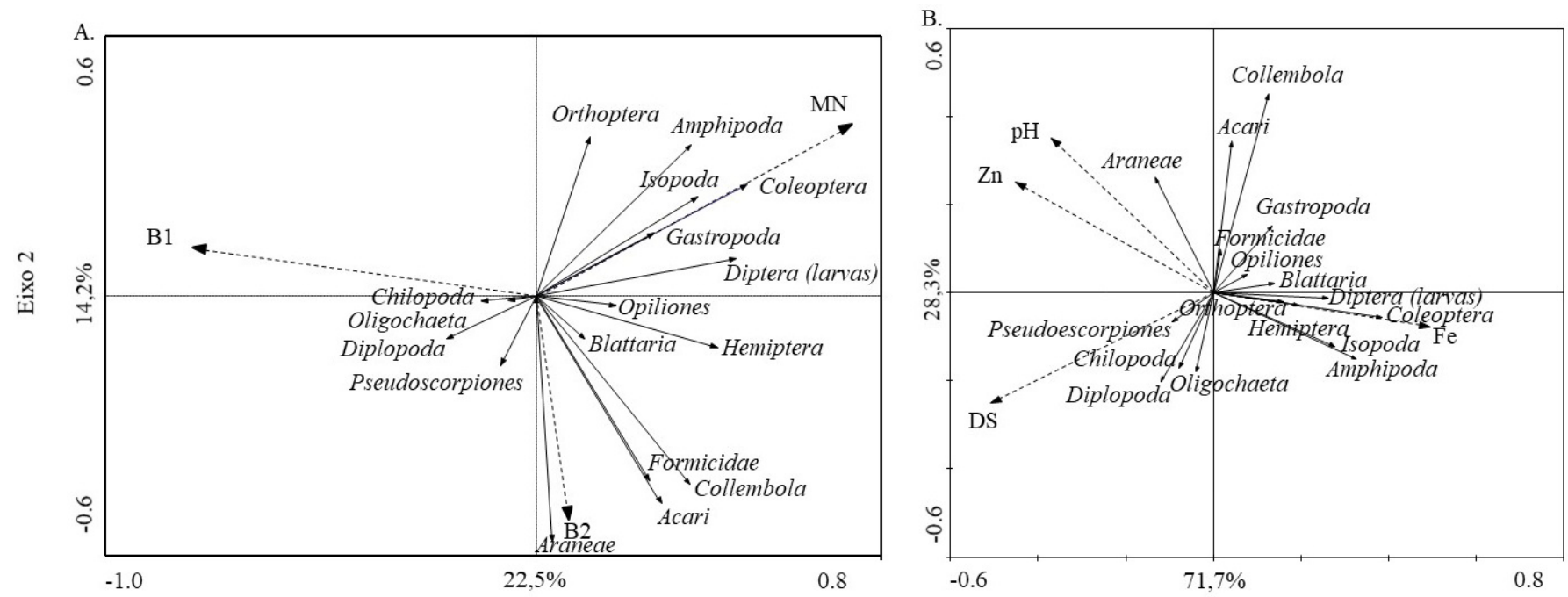

Eixo 1

Figura 2. Análise de componentes principais (PCA) (A) e análise de redundância (RDA) (B) para a coleta através de armadilhas de queda em dezembro de 2015. 
dos vetores que representam as áreas. Percebe-se que B1 está associado a um menor número de grupos e os vetores que representam esses grupos estão próximos ao centro, o que indica baixa correlação (Rosa et al., 2015). Ao comparar estes resultados com os da Tabela 2, em dezembro para as armadilhas de queda, B1 apresentou uma menor abundância e riqueza média que as demais áreas. Já o vetor que representa $\mathrm{MN}$, está associado a um maior número de grupos e possui vetores maiores, indicando maior correlação. O vetor que representa B2 também está associado a diversos grupos com vetores afastados do centro (alta correlação). No entanto, os grupos associados a B2 são diferentes dos associados a $\mathrm{MN}$, indicando uma distribuição de grupos diferente nestas áreas. A Tabela 2 demonstra que na coleta de dezembro por armadilhas de queda, a MN e B2 não apresentam diferenças significativas para média de organismos e riqueza. Como já discorrido, dezembro foi a época onde maior número de organismos foram coletados, também foi o período onde as maiores riquezas foram registradas. Nesse sentido, a maior pluviosidade de dezembro com efeitos, na umidade do solo, pode ter afetado positivamente os grupos da fauna em B2 e $M N$, não tendo o mesmo efeito em B1.

$\mathrm{Na}$ RDA (Figura 2B), as VAE selecionadas foram o $\mathrm{Zn}^{+2}$ e o $\mathrm{pH}$ que demonstraram relação principalmente com Collembola, Acari e Araneae já o $\mathrm{Fe}^{+3}$, têm relação com Coleoptera, Diptera (larvas), Hemiptera, Orthoptera, Amphipoda e Isopoda e a DS (densidade do solo) relaciona-se principalmente com Diplopoda.

Quanto ao elemento $\mathrm{Zn}^{+2}$, este apresenta afinidade com a matéria orgânica do solo e é também, um importante micronutriente para a bananeira (Melo et al., 2008; Pereira et al., 2012). Os teores de $\mathrm{Zn}^{+2}$ no solo estão relacionados com os resíduos das plantas depositadas sobre o mesmo (Dechen \& Nachtigall, 2006). Desse modo, a constituição do material vegetal disposto nos bananais, pode ter influência sobre o maior teor de $\mathrm{Zn}^{+2}$ no solo nas áreas produtivas (Tabela 3) e consequentemente, sobre fauna edáfica. Nesse aspecto, o grupo Collembola é influenciado pela qualidade do substrato depositado no solo já que, participa dos processos de degradação da serapilheira, pois tem como fonte alimentar a microbiota (decompositores) e matéria orgânica do solo (Oliveira Filho et al., 2016). Já o grupo Araneae pode ser indiretamente influenciado pelo substrato orgânico e o teor de $Z^{+2}$ já que, o material orgânico tem efeito positivo sobre
Collembola, grupo de organismos predados por Araneae (Podgaiski \& Rodrigues, 2017). Da mesma forma existe relação de predação entre os grupos Acari e Collembola (Silva et al., 2013) e o grupo Acari é também influenciado pela matéria orgânica aportada ao solo (Almeida et al., 2017).

Tratando-se do $\mathrm{pH}$, o maior valor do parâmetro foi verificado nos bananais (Tabela 3), sendo resultado da calagem. Segundo Almeida et al. (2007), esta prática afeta a camada superior com alterações na química do solo e tem efeito sobre outros aspectos como a porosidade, densidade e a biologia do solo, afetando indiretamente a fauna edáfica. $\mathrm{Na}$ avaliação das áreas, B2 tem pH maior que B1, possivelmente em função da calagem ter sido realizada na área mais recentemente que em B1 (Tabela 1$)$.

Dentre os grupos que demostram relação com o pH, Araneae faz parte dos predadores do solo, associados com a qualidade do ambiente e a uma maior complexidade de interações ecológicas entre a fauna do solo (Baretta et al., 2010). Portanto, a calagem nos bananais e a melhora da qualidade química, física e biológica do solo decorrente desta prática, pode ter melhorado a qualidade do habitat da fauna e em consequência, favorecido o grupo Araneae e sua atividade de predação.

O grupo Collembola também se mostrou relacionado ao $\mathrm{pH}$, o maior valor do parâmetro decorrente da calagem em B1 e B2 pode ter favorecido o grupo uma vez que, este responde as mudanças de $\mathrm{pH}$ advindas do manejo do solo (Silva et al., 2016). A calagem, com consequente elevação do pH, somada a existência de cobertura de solo (restos culturais) nos bananais pode ter beneficiado o grupo Acari, principalmente em B2 (maior pH) já que, no estudo de Giracca et al. (2008), a elevação do $\mathrm{pH}$ através da calagem em áreas com cobertura de solo (plantio direto) teve efeito positivo sobre o grupo Acari.

O conteúdo de $\mathrm{Fe}^{+3}$ está relacionado com a mineralogia e com os complexos formados com a matéria orgânica do solo (Sial \& Mcreath, 1984; Dechen \& Nachtigall, 2006; Brandy \& Wield, 2013). O material vegetal depositado no solo advindo da vegetação natural da $\mathrm{MN}$ pode influenciar a matéria orgânica do solo e o maior conteúdo de $\mathrm{Fe}^{+3}$ nesta área (Tabela 3) e, em consequência, o metabolismo dos organismos que se alimentam da serapilheira sobretudo, dos que demonstraram maior relação com o $\mathrm{Fe}^{+3}$, como Coleoptera, Diptera (larvas), Hemiptera, Orthoptera, Amphipoda e Isopoda. Estes grupos

Tabela 3. Atributos químicos e físicos do solo selecionados como Variáveis Ambientais Explicativas (VAE) dos grupos da fauna edáfica nas áreas de produção de banana (B1 e B2) e na mata nativa (MN) (média \pm desvio padrão).

\begin{tabular}{lccc}
\hline \multicolumn{1}{c}{ VAE } & MN & B1 & B2 \\
\hline $\mathrm{pH} \mathrm{em} \mathrm{H} 2 \mathrm{O}$ & $5,14 \pm 0,51 \mathrm{c}$ & $5,76 \pm 0,38 \mathrm{~b}$ & $6,95 \pm 0,23 \mathrm{a}$ \\
$\mathrm{Fe}^{+3}\left(\mathrm{mg} \mathrm{dm}^{-3}\right)$ & $375,03 \pm 216,37 \mathrm{a}$ & $147,4 \pm 36,65 \mathrm{~b}$ & $196,71 \pm 163,42 \mathrm{ab}$ \\
$\mathrm{Zn}^{+2}\left(\mathrm{mg} \mathrm{dm}^{-3}\right)$ & $44,13 \pm 21,55 \mathrm{~b}$ & $118,8 \pm 29,63 \mathrm{a}$ & $164,94 \pm 78,37 \mathrm{a}$ \\
$\mathrm{Al}^{+3}\left(\mathrm{cmol} \mathrm{dm}^{-3}\right)$ & $0,87 \pm 0,83 \mathrm{a}$ & $0,08 \pm 0,09 \mathrm{~b}$ & $0,00 \pm 0,00 \mathrm{~b}$ \\
$\mathrm{Mg}^{+2}\left(\mathrm{cmol} \mathrm{dm}^{-3}\right)$ & $2,78 \pm 0,83 \mathrm{~b}$ & $2,85 \pm 0,66 \mathrm{~b}$ & $10,05 \pm 2,64 \mathrm{a}$ \\
$\mathrm{Ca}^{+2}\left(\mathrm{cmol} \mathrm{dm}^{-3}\right)$ & $6,75 \pm 8,30 \mathrm{~b}$ & $9,24 \pm 2,04 \mathrm{~b}$ & $34,17 \pm 6,16 \mathrm{a}$ \\
Macroporosidade (Macro) $\left(\mathrm{m}^{3} \mathrm{~m}^{-3}\right)$ & $0,13 \pm 0,03 \mathrm{a}$ & $0,11 \pm 0,25 \mathrm{a}$ & $0,11 \pm 0,04 \mathrm{a}$ \\
Densidade do Solo (DS) $\left(\mathrm{g} \mathrm{cm}^{3}\right)$ & $1,02 \pm 0,15 \mathrm{~b}$ & $1,40 \pm 0,13 \mathrm{a}$ & $1,13 \pm 0,80 \mathrm{~b}$ \\
\hline
\end{tabular}

*Letras iguais na linha representam tratamentos que não apresentam diferenças significativas pelo teste de Tukey $(p>0,05)$. MN = mata nativa, $\mathrm{B} 1=$ bananal $1, \mathrm{~B} 2=$ bananal 2 . 
são classificados como detritívoros/decompositores (Brown et al., 2015) e são, portanto, dependentes do material vegetal depositado no solo e possivelmente dos teores de $\mathrm{Fe}^{+3}$ deste material.

Levando em consideração a DS, Diplopoda mostra relação positiva com a variável. Este grupo está presente apenas em B1, área de maior DS, representando organismos de superfície que vivem na serapilheira, sendo detritívoros e movimentando-se entre os restos vegetais (Brown et al., 2015; Brusca et al., 2016). Por viverem na superfície estes organismos podem ter sido menos afetados pela maior DS do que outros grupos, fazendo parte dos organismos coletados em B1, ainda que em pequena abundância.

Os grupos que apresentaram relação negativa com a DS são: detritívoros (Acari, Collembola, Gastropoda e Blattaria) e/ou predadores (Opiliones e Acari) (Brown et al., 2015). Os grupos detritívoros e predadores não são dependentes da DS (Rosa et al., 2015). Nesse sentido, a relação negativa destes grupos com a DS pode se dar por algum efeito indireto da física do solo sobre estes organismos.

$\mathrm{Na}$ análise multivariada da coleta de abril de 2016 para as armadilhas de queda observa-se a proximidade entre os vetores que representam B1 e B2 na Figura 3A, demonstrando similaridade entre a distribuição dos grupos presentes nestas áreas enquanto, a MN apresenta uma distribuição de grupos diferente dos bananais, representada pela distância do vetor que corresponde à área em relação aos demais (Figura 3A). Os grupos Acari, Collembola e Formicidae podem ser importantes para caracterizar a semelhança entre os bananais já que, representam a maior parte da abundância destas áreas (B1 = $92 \%$ e B2 = 93\%) já o grupo mais representativo da MN nesta coleta, é o Coleoptera, correspondendo a $15 \%$ da abundância total de organismos da MN e apresentando relação com esta área segundo a PCA.
Na RDA para a coleta de abril de 2016 (Figura 3B) dentre as VAE selecionadas pelo modelo o pH demostrou relação principalmente com Collembola, Acari, Diplopoda e Formicidae já o $\mathrm{Fe}^{+3}$, com Amphipoda, Diptera (larvas), Hemiptera e Isopoda e o $\mathrm{Al}^{+3}$ demostrou interação com Coleoptera.

$\mathrm{O}$ fato do $\mathrm{pH}$ ter sido verificado como VAE da fauna demostra que, a calagem com alterações no pH solo, é uma prática agrícola que influencia a fauna edáfica e também diferencia os grupos de organismos de áreas produtivas das áreas naturais e sem manejo, como a MN. Verifica-se que na coleta de abril por armadilhas de queda, o pH demonstra relação com os grupos Acari e Collembola, o quais já haviam demonstrado relação com o parâmetro na coleta anterior (dezembro), confirmando a importância do $\mathrm{pH}$ para estes grupos.

A relação do grupo Formicidae com o $\mathrm{pH}$ pode ser entendida de forma indireta, pois a elevação do $\mathrm{pH}$ por meio da calagem aumenta a atividade microbiana (Mijangos et al., 2010) fazendo parte da comunidade de microrganismos os fungos, fonte alimentar de alguns organismos dentro do grupo Formicidae (Rocha et al., 2015). Acredita-se, portanto, que o aumento na atividade microbiana em função da elevação do $\mathrm{pH}$ pode prover maiores recursos alimentares para Formicidae e estimular a sua abundância nos bananais, áreas de maior $\mathrm{pH}$ em função da calagem.

Segundo Almeida et al. (2007), mesmo quando a fauna não apresenta correlação direta com a calagem podem haver interferências indiretas desta prática agrícola aos organismos edáficos através da maior produtividade vegetal que representa para fauna substrato alimentar e proteção através da cobertura do solo. Desse modo, o grupo Diplopoda por ser detritivoro e habitar a serapilheira (Brown et al., 2015), pode ter sido influenciado positivamente pela calagem com elevação do pH em B2 (maior abundância) em função do maior
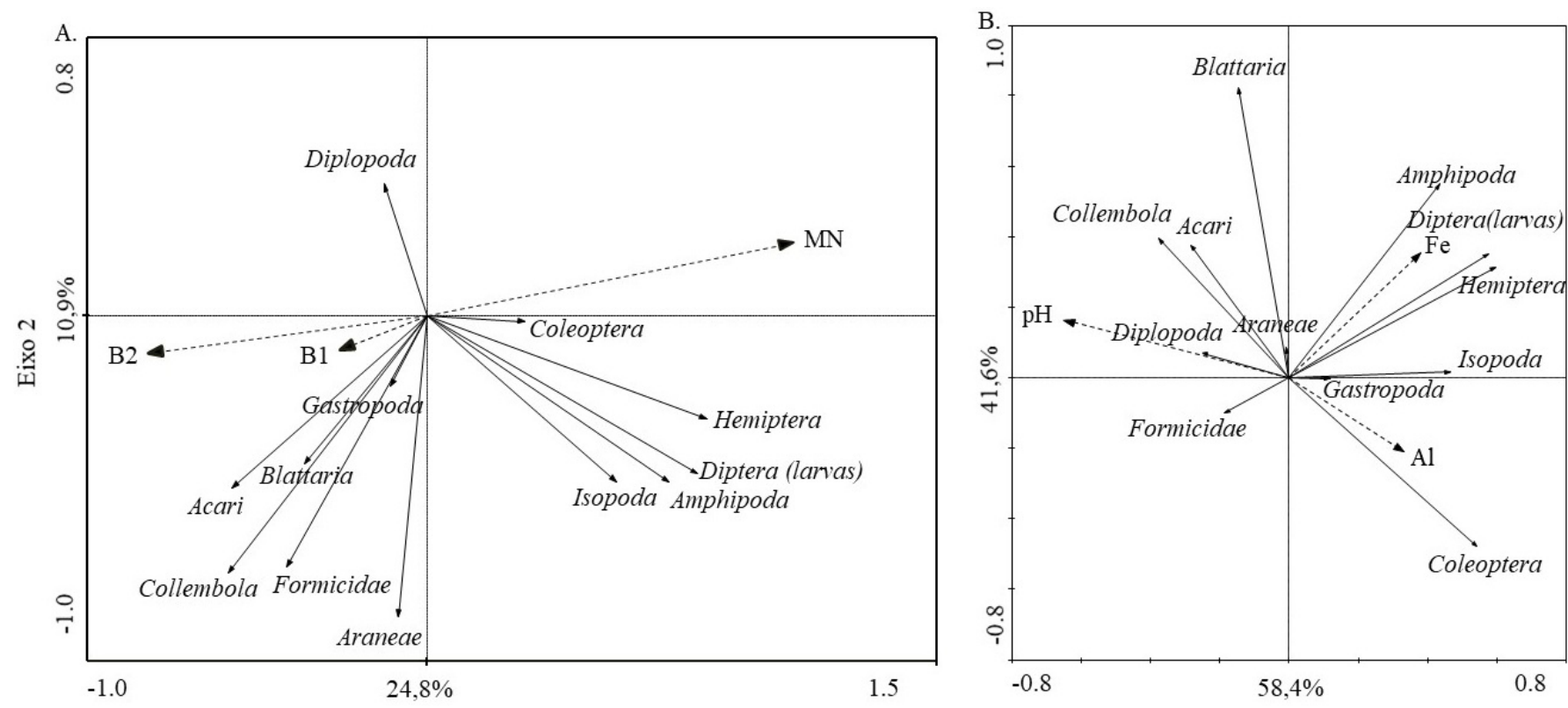

Eixo 1

Figura 3. Análise de componentes principais (PCA) $(A)$ e análise de redundância (RDA) (B) para a coleta através de armadilhas de queda em abril de 2016. 
rendimento da fitomassa das bananeiras e em consequência, pelo maior volume de restos vegetais depositados na superfície do solo.

Nos bananais, a cobertura de solo é resultado da deposição dos restos culturais no solo (restos da desfolha e de colheita). Na cultura da banana, a deposição dos resíduos culturais é elevada e constante devido à alta produção de fitomassa das bananeiras e ainda, pelo fato da bananeira ser uma herbácea perene. Em torno de $66 \%$ da massa vegetativa das bananeiras é disposta no solo na forma de restos culturais (Borges \& Souza, 2004; Moreira \& Fageria, 2009).

Outro resultado que indica o efeito da calagem ou então, da não aplicação da técnica, é a significância do $\mathrm{Al}^{+3}$ como VAE, sendo o maior teor do elemento encontrado na MN (Tabela 3), em função da não correção da acidez através da calagem. Esse resultado pode indicar que, as espécies vegetais da $\mathrm{MN}$, mesmo com valores mais altos de $\mathrm{Al}^{+3}$ que as áreas com calagem (bananais), se desenvolvem e produzem material vegetal que ao ser depositado no solo forma a serapilheira necessária para presença de Coleoptera e outros grupos da fauna. Rosa et al. (2015) trabalharam em diferentes usos de solo e considerou que a distribuição do grupo Coleoptera estava ligada a cobertura vegetal e o habitat fornecido por esta.

Na segunda coleta através de armadilhas de queda, o $\mathrm{Fe}^{+3}$ demostrou relação com alguns dos mesmos grupos da primeira coleta (Amphipoda, larvas de Diptera, Hemiptera e Isopoda) sendo a abundância destes grupos, novamente maior na MN. Este resultado reforça a relação destes grupos com a $\mathrm{MN}$ e com as características edáficas apresentadas pela área. $\mathrm{O} \mathrm{Fe}{ }^{+3}$ é um elemento ligado a matéria orgânica e da mineralogia do solo (Sial \& Mcreath, 1984; Dechen \& Nachtigall, 2006; Brandy \& Wield, 2013). Portanto, a caraterística da MN de apresentar maiores teores de $\mathrm{Fe}^{+3}$, pode afetar indiretamente a fauna edáfica pela sua relação, principalmente com a matéria orgânica do solo, da qual depende a fauna edáfica.

Na Figura 4A, tem-se a PCA para o mês de dezembro de 2015 na coleta pelo monólito de solo onde, o Eixo 1 indica a separação dos vetores que representam os bananais do vetor que corresponde a MN. Essa representação demonstra similaridade entre as áreas produtivas e uma condição de grupos da fauna do solo distinta para a MN. Os grupos que contribuíram para a separação da $\mathrm{MN}$ das demais áreas foram principalmente, Amphipoda, Isopoda, Opiliones, Hemiptera, Hirudienea e Orthoptera que somam $17 \%$ da densidade de organismos na MN e representam grupos de maior densidade nesta do que, nas demais áreas.

Na RDA na coleta pelo monólito de solo em dezembro de 2015 (Figura 4B) no que tange as VAE a DS está relacionada os grupos Formicidae e Diplopoda, Termitoidade e Gastropoda. O $\mathrm{pH}, \mathrm{Ca}^{+2}$ e $\mathrm{Mg}^{+2}$ demostram relação com os grupos Chilopoda e Dermaptera.

No que se refere DS, os grupos Diplopoda e Gastropoda, relacionados a este parâmetro, por serem detritivoros e se movimentaram na superfície do solo, ou seja, na serapilheira (Brown et al., 2015; Brusca et al., 2016) parecem não ter sido prejudicados mesmo em situação de maior DS. Esse fato é verificado pela maior abundância de Diplopoda e Gastropoda em B1 (maior DS). Os grupos Formicidae e Termitoidae (cupins) podem estabelecer-se em diferentes nichos do ambiente edáfico como a superfície do solo, a serapilheira e o solo subterrâneo (Moreira et al., 2008). Por esse motivo, estes grupos podem ter sido menos afetados pela DS, apresentando maior abundância em B1.

O grupo Oligochaeta demonstra relação negativa com a DS, fato que pode ser explicado pela necessidade de um maior
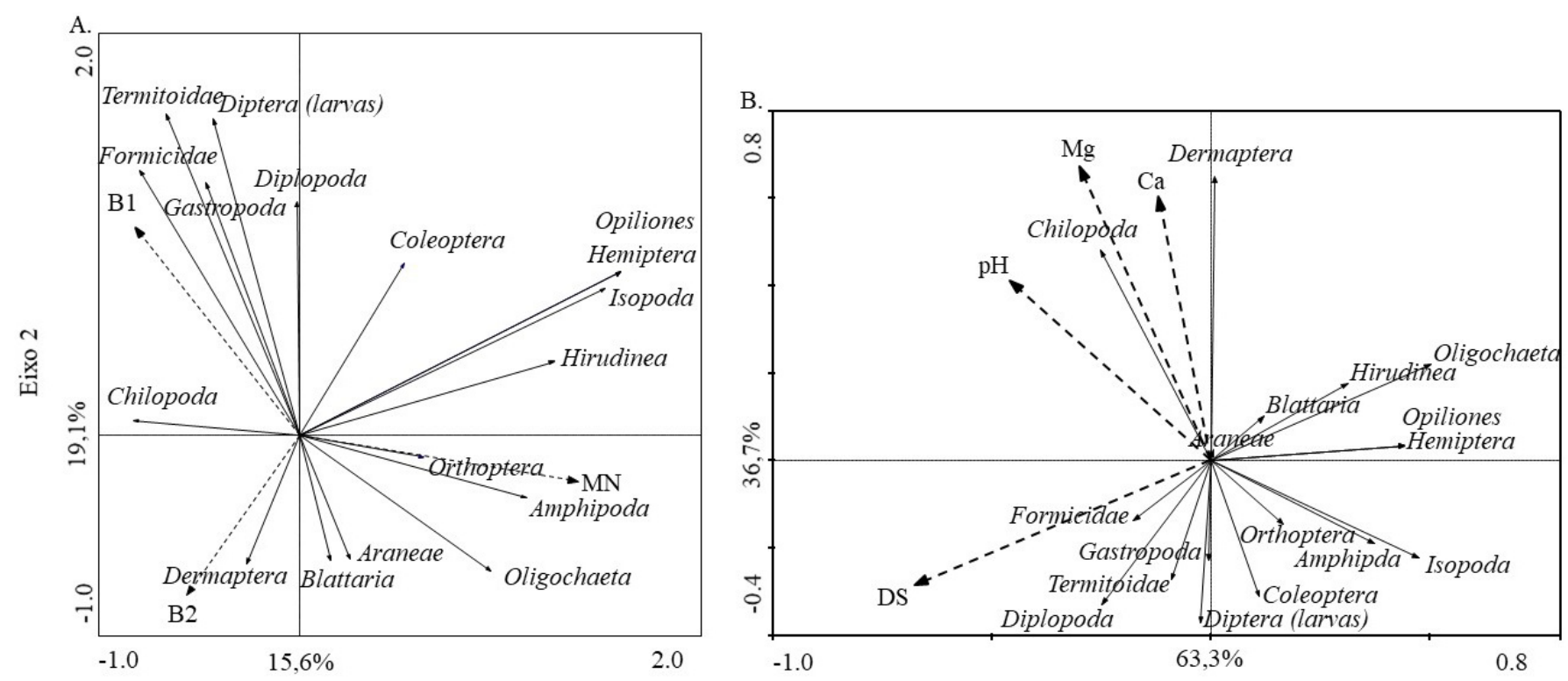

Eixo 1

Figura 4. Análise de componentes principais (PCA) (A) e análise de redundância (RDA) (B) para a coleta através de monólito de solo na em dezembro de 2015. 
espaço poroso pelo grupo pois, constitui-se de organismos que se estabelecem em função das condições físicas do solo e dependem da escavação para sua mobilidade e alimentação (Brown \& Domíngez, 2010; Brusca et al., 2016). Nesse sentido, esta relação negativa entre Oligochaeta e a DS ajuda a entender a menor abundância do grupo em B1, área de maior DS. Outro grupo que apresenta uma correlação negativa com a DS é o Hirudinea (sanguessugas terrestres). Este grupo é predador de minhocas (Oligochaeta) (Schiedeck et al., 2009). Assim, se o ambiente é desfavorável para o grupo Oligochaeta, consequente o grupo Hirudinea será prejudicado. Além da questão da predação, o grupo Hirudinea também pode ser um grupo de organismos escavadores (Ventura et al., 2010). Portanto, a maior DS também pode ser negativa para esses organismos.

Os maiores valores de $\mathrm{Mg}^{+2}$ e $\mathrm{Ca}^{+2} \mathrm{e} \mathrm{pH}$, foram observados em B2 (Tabela 3), possivelmente em função da calagem mais recente nesta área, os maiores valores de abundância de Chilopoda e Dermaptera também foram encontrados em B2. De acordo com o estudo de Baretta et al. (2014), $\mathrm{Mg}^{+2} \mathrm{e}$ $\mathrm{Ca}^{+2}$ e pH estão associados com as condições químicas do solo sendo que, o aumento destes parâmetros resulta em maior fertilidade do solo e melhoras na atividade biológica. Partindo desta premissa, locais com melhor fertilidade, indiretamente podem beneficiar a fauna, através da melhora no rendimento vegetal, nas interrelações entre o sistema solo-planta e por sua vez, mais organismos da meso e macrofauna podem ser atraídos para este ambiente, essa observação é bastante pertinente, pois trata-se de uma desconstrução histórica de que áreas manejadas poderiam suprimir todos os grupos de invertebrados do solo.

Os grupos relacionados com $\mathrm{Mg}^{+2}, \mathrm{Ca}^{+2}$ e $\mathrm{pH}$ são predadores (Chilopoda e Dermaptera) e decompositores/

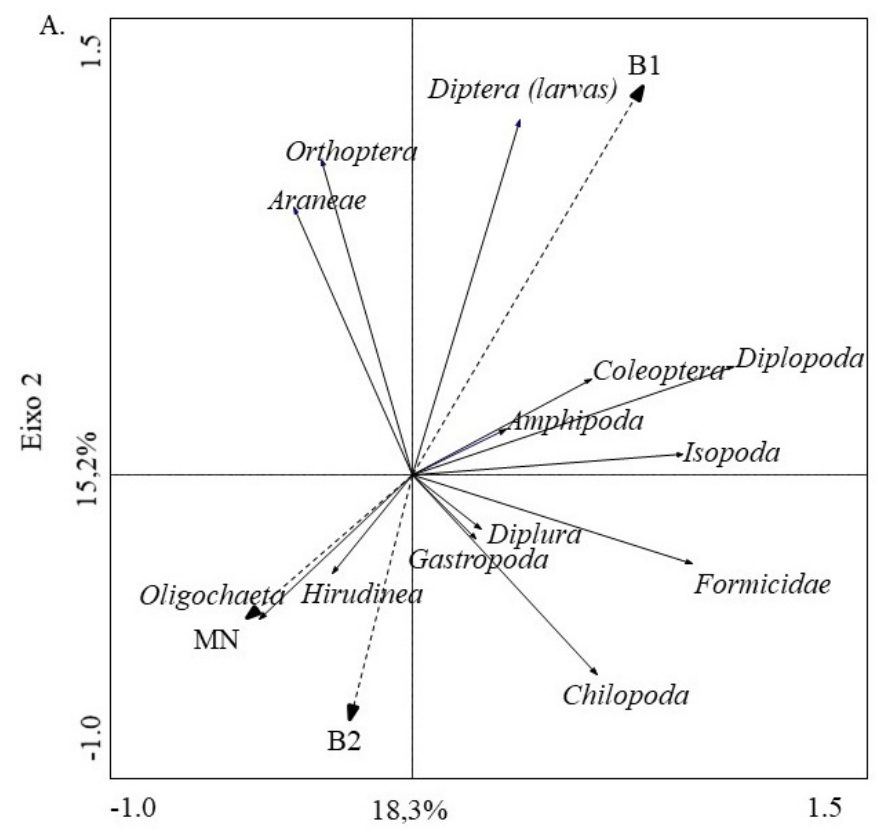

detritívoros (Dermaptera) (Brown et al., 2015). Desse modo, Dermaptera pode se beneficiar diretamente pela quantidade de recursou alimentar e ambos os grupos podem beneficiar-se indiretamente pelo possível aumento na abundância da fauna a ser predada por estes grupos, em função da maior oferta de recursos alimentares, disponibilizados pelos resíduos vegetais que são depositados sob o solo.

Apesar da MN também oferecer grande oferta e variedade de material vegetal como recurso alimentar para a fauna, a deposição deste recurso no solo está sujeita a deposição natural do material. Nesse sentido, a taxa de formação da serapilheira em áreas nativas foi averiguada em um estudo realizado em Floresta Ombrófila Mista e clima Cfa, verificando que em 21 meses, a média da serapilheira acumulada em áreas de estágio sucessional avançado de regeneração era de 5,28 t/ha o que para um ano, representaria cerca de 3 t ha-1 (Caldeira et al., 2008). Já nas áreas de produção de banana, a oferta de recursos alimentares para fauna vem da deposição dos restos culturais sendo que, a cultura da banana pode produzir e depositar no solo 10 a $15 \mathrm{t} \mathrm{ha}^{-1} \mathrm{ano}^{-1}$ de restos culturais (restos da desfolha e colheita) (Borges et al., 2003).

Para o monólito de solo na coleta de abril de 2016 a separação do vetor que representa $\mathrm{B} 1$ das demais áreas por meio do Eixo 1, expresso graficamente na PCA da Figura 5A, demonstra similaridade na distribuição dos grupos da fauna edáfica entre a MN e B2 e uma condição diferente desta distribuição para B1. A MN e B2 mostraram-se fortemente relacionadas ao grupo Oligochaeta que, representa a maior parte do total de organismos amostrados através do monólito de solo nestas áreas. Verifica-se para B1, forte relação entre esta área o grupo Diptera (larvas), grupo com maior abundância em B1 na coleta de abril.

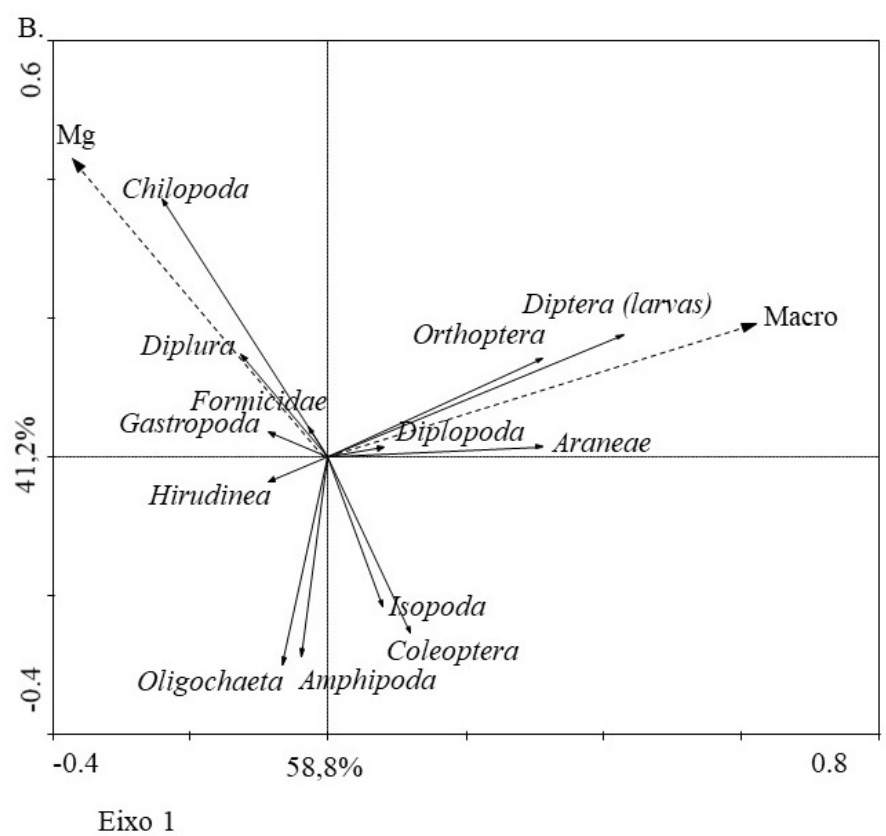

Figura 5. Análise de componentes principais (PCA) (A) e análise de redundância (RDA) (B) para a coleta através de monólito de solo em abril de 2016. 
A RDA para o monólito de solo na coleta de abril de 2016 (Figura 5B) indica como VAE a Macro (macroporosidade) e o $\mathrm{Mg}^{+2}$ sendo, a primeira relacionada principalmente com Diptera (larvas) e a segunda com os grupos Chilopoda e Diplura. Os grupos relacionados com as VAE têm suas maiores densidades em B1 (larvas de Diptera) e B2 (Chilopoda e Diplura) sendo que, não existem diferenças significativas para a Macro das áreas e o maior conteúdo de $\mathrm{Mg}^{+2}$ foi averiguado em B2 (Tabela 3).

No que se refere a Macro e sua correlação é principalmente com o grupo Diptera (larvas). Este grupo é parte importante em termos de abundância da fauna do solo em muitos ecossistemas, embora esteja no solo apenas na fase larval. Estes organismos vivem em condições semelhantes a larvas de outros organismos inteiramente edáficos, movendo-se lentamente no solo. Quanto aos papéis desempenhados no solo podem ser saprófagos, fungívoros e predadores (Frouz, 1999). No presente estudo, o grupo Diptera (larvas) concentra sua abundância nas áreas de produção de banana. Assim, sugere-se que, a mobilidade ainda que lenta desse grupo para cumprir suas funções no solo, pode afetar positivamente a macroporosidade do solo nestas áreas.

O $\mathrm{Mg}^{+2}$ é um nutriente essencial para as plantas adicionado ao solo através da calagem. Este macronutriente é importante para desenvolvimento de qualquer cultivo, influenciando diretamente sua produtividade (Toledo Neto et al., 2005). Nesse sentido, o maior teor de $\mathrm{Mg}^{+2}$ em B2 explica-se pela calagem mais recente nesta área (Tabela 3). Já a relação do $\mathrm{Mg}^{+2}$ com o grupo Diplura (detritívoro) (Brown et al., 2015), pode dar-se indiretamente através, do aumento no rendimento vegetal das bananeiras e em consequência a maior disponibilidade se resíduos na superfície do solo. Quanto ao grupo Chilopoda (predador) (Brown et al., 2015) sua relação com $\circ \mathrm{Mg}^{+2}$ pode ser também indireta sendo estes predadores, beneficiados pelas melhores condições de substrato alimentar para os grupos por ele predados.

\section{Conclusões}

As práticas culturais e o manejo dado a cada bananal têm influência sobre fauna edáfica. As principais práticas que se relacionam com a fauna são a calagem, adubação e disposição dos restos culturais no solo. Os grupos que mais contribuem na abundância total de organismos amostrados nos bananais são: Acari, Collembola, Coleoptera, Diptera (larvas), Formicidae e Oligochaeta.

\section{Literatura Citada}

Almeida, H.C.; Almeida, D.; Alves, M.V.; Schneider, J.; Mafra, A.L; Bertol, I. Propriedades químicas e fauna do solo influenciadas pela calagem em sistema semeadura direta. Ciência Rural, v.37, n.5, p.1462-1465, 2007. https://doi.org/10.1590/S010384782007000500040 .
Almeida, H.S.; Silva, R.F.; Grolli, A.L.; Scheid, D.L. Ocorrência e diversidade da fauna edáfica sob diferentes sistemas de uso do solo. Revista Brasileira de Tecnologia Agropecuária, v.1, n.1, p.15-23, 2017. http://revistas.fw.uri.br/index.php/rbdta/article/ view/2162/2269. 05 Set. 2018.

Alves, E.J.; Lima, M.B.; Santos-Serejo, J.A.; Trindade, A.V. Propagação. In: Borges, L.S; Souza, A.L. (Eds.). O cultivo da banananeira. Cruz das Almas: Embrapa Mandioca e Fruticultura, 2004. p.5986. http://www.infoteca.cnptia.embrapa.br/infoteca/handle/ doc/1005043. 22 Jun. 2018.

Anderson, J.M.; Ingram, J.S.I. (Eds.). Tropical soil biology and fertility: a handbook of methods. 2.ed. Wallingford: CAB International, 1993. 221p.

Aquino, A.M; Correia, M.E.F. Invertebrados edáficos e o seu papel nos processos do solo. Seropédica: Embrapa Agrobiologia, 2005. 52p. (Embrapa Agrobiologia. Documentos, 201). https://ainfo. cnptia.embrapa.br/digital/bitstream/CNPAB-2010/33061/1/ doc201.pdf. 25 Ago. 2018.

Arcoverde, S.N.S.; Salviano, A.M.; Olszevski, N.; Melo, S.B.; Cunha, T.J.F.; Giongo, V.; Pereira, J.S. Qualidade física de solos em uso agrícola na região semiárida do estado da Bahia. Revista Brasileira de Ciência do Solo, v.39, n.5, p.1473-1482, 2015. https://doi.org/ 10.1590/01000683rbcs20140282.

Balin, N.M.; Bianchini, C.; Ziech, A. R.D.; Luchese, A.V.; Alves, M.V.; Conceição, P. C. Fauna edáfica sob diferentes sistemas de manejo do solo para produção de cucurbitáceas. Revista Scientia Agraria, v.18, n.3, p.74-84, 2017. https://doi.org/10.5380/rsa. v18i3.52133.

Baretta, D.; Bartz, L. M. C.; Fachini, I.; Anselmi, R.; Zortéa, T.; Duarte, C.R.; Baretta, M. Soil fauna and its relation with environmental variables in soil management systems. Revista Ciência Agronômica, v.45, n.5 (especial), p.871-879, 2014. http://ccarevista.ufc.br/seer/index.php/ccarevista/article/ view/3477/1030. 29 Mar. 2018.

Baretta, D.; Brown, G.G.; Cardoso, E.J.B.M. Potencial da macrofauna e outras variáveis edáficas como indicadores da qualidade do solo em áreas com Araucaria angustifolia. Acta Zoológica Mexicana, v.26, n. especial 2, p.135-150, 2010. https://doi.org/10.21829/ azm.2010.262883.

Baretta, D.; Santos, J.C.P.S.; Segat, J.C.; Geremia, E.V.; Oliveira Filho, L.C.I.; Alves, M.V. Fauna edáfica e qualidade do solo. Tópicos Especiais em Ciência do Solo, v.7, p.119-170, 2011.

Borges, A.L.; Trindade, A.V.; Souza, L.S.; Silva, M.N.B. Cultivo orgânico de fruteiras tropicais. Cruz das Almas: Embrapa Mandioca e Fruticultura, 2003. CD-Rom. (Embrapa Mandioca e Fruticultura. Circular Técnica, 64).

Borges, L.S; Souza, A.L. Exigências edafoclimáticas. In. Borges, L.S; Souza, A.L. (Eds.). O cultivo da bananeira. Cruz das Almas: Embrapa Mandioca e Fruticultura, 2004. p.15-23. https://ainfo. cnptia.embrapa.br/digital/bitstream/item/142900/1/LivroBanana.pdf. 19 Mar. 2018.

Brandy, N.C; Weil, R.R. Elementos da natureza e propriedades dos solos. 3.ed. Porto Alegre: Bookman, 2013. 704p.

Brown, G.G.; Domínguez, J. Uso das minhocas como bioindicadoras ambientais: princípios e práticas - o 3 o Encontro Latino Americano de Ecologia e Taxonomia de Oligoquetas (Elaetao3). Acta Zoológica Mexicana, v.26, n. especial 2, p.1-18, 2010. https://doi. org/10.21829/azm.2010.262874. 
Brown, G.G.; Niva, C.C.; Zagatto, M.R.G.; Ferreira, S.A.; Nadolny, H.S.; Cardoso, G.B.X.; Martinez, A.S.G.A.; Pasini, A.; Bartz, M.L.C.; Sautter, K.D.; Thomazini, M.J., Baretta, D.; Silva, E.; Antoniolli, Z.I.; Decaëns, T.; lavelle, P. M. Sousa, J. P.; Carvalho, F. Biodiversidade da fauna do solo e sua contribuição para os serviços ambientais. In: Parron, L.M.; Garcia, J.R; Oliveira, E.B.; Brown, G.G.; Prado, R.B. (Eds.). Serviços ambientais em sistemas agrícolas e florestais do bioma mata atlântica. Colombo: Embrapa Florestas, 2015. Cap. 10, p.122-154. https://ainfo.cnptia.embrapa.br/digital/ bitstream/item/131969/1/Livro-Servicos-Ambientais-Embrapa. pdf. 29 Mar. 2018.

Brusca, R. C.; Moore, W.; Shuster, S.M. Invertebrates. 3.ed. Sunderland: Sinauer Associates, 2016. 1104p.

Caldeira, M.V.W.; Vitorino, M.D.; Schaadt, S.S.; Moraes, E.; Balbinot, R. Quantificação de serapilheira e de nutrientes em uma Floresta Ombrófila Densa. Semina: Ciências Agrárias, v. 29, n. 1, p. 53-68, 2008. https://doi.org/10.5433/1679-0359.2008v29n1p53.

Dechen, A.R; Nachtigall, G.R. Elementos essenciais e benéficos as plantas superiores. In: Fernandes, M.S. (Ed.). Nutrição mineral de plantas. Viçosa: Sociedade Brasileira de Ciência do Solo, 2006. p.1-5.

Empresa Brasileira de Pesquisa Agropecuária - Embrapa. Centro Nacional de Pesquisa de Solos. Manual de métodos de análises de solo. 2.ed. Rio de Janeiro: Embrapa, 1997. 212p.

Estado de Santa Catarina. Inventário florístico florestal de Santa Catarina. Blumenau: Estado de Santa Catarina, 2015. 7p. (IFFSC. Boletim 14). http://ciram.epagri.sc.gov.br/ciram_arquivos/ arquivos/iff/pdf/BoletinsMeta2/boletim14_iffsc_set_2015.pdf. 10 Mar. 2018.

Food and Agriculture Organization of the United Nations - FAO. Faostat: Food and agriculture data. Productions. Crops: bananas - 2016. http://faostat3.fao.org/browse/Q/QC/E. 05 Nov. 2017.

Frouz, J. Use of soil dwelling Diptera (Insecta, Diptera) as bioindicators: a review of ecological requirements and response to disturbance. Agriculture, Ecosystems \& Environment, v. 74, n.1-3, p. 167-186, 1999. https://doi.org/10.1016/S0167-8809(99)00036-5.

Giracca, E.M.N.; Antoniolli, Z.I.; Steffen, R.B.; Steffen, G.P.K.; Schirmer, G. K.; Eltz, F.L.F. Influência da aplicação de calcário na população da meso e macrofauna do solo sob sistema plantio direto. Ciência e Agrotecnologia, v.32, n.6, p.1794-1801, 2008. https://doi. org/10.1590/S1413-70542008000600018.

Guimarrães, N.F.; Gallo, A.S.; Souza, M. D. B.; Agostinho, F. R.; Gomes, M. S.; Silva, R. F. Influência dos sistemas de produção de café orgânico arborizado sobre a diversidade da fauna edáfica epigéica. Coffee Science, v. 10, n. 3, p. 280 - 288, 2015. https:// doi.org/10.25186/cs.v10i3.843.

Instituto Brasileira de Geografia e Estatística - IBGE. Levantamento sistemático da produção agrícola: pesquisa mensal de previsão e acompanhamento das safras agrícolas no ano civil. Levantamento Sistemático da Produção Agrícola, v.29, n.8, p.1-79, 2016. ftp:// ftp.ibge.gov.br/Producao_Agricola/Levantamento_Sistematico_ da_Producao_Agricola_\%5Bmensal\%5D/Fasciculo/2016/ Ispa_201608.pdf. 10 Mar. 2018.

Instituto Nacional de Meteorologia - INMET. Estação automática de Urussanga. 2016. http://www.inmet.gov.br/portal/index. php?r=home/page\&page=rede_estacoes_auto_graf. 07 Set.2018.
Israeli, Y.; Lahav, E. Tropical agriculture: banana. In: Thomas, B.; Murphy, D.J.; Murray, B.G. (Eds.). Encyclopedia of Applied Plant Sciences. 2.ed. London: Academic Press, 2017. v.3, p.363-381.

Lichtemberg, L.A; Lichtemberg, P.S.F. Avanços na bananicultura brasileira. Revista Brasileira de Fruticultura, v.33. n. spe1, p.2936, 2011. https://doi.org/10.1590/S0100-29452011000500005.

Melo, E.E.C.; Nascimento, C.W.A.; Santos, A.C.Q.; Silva, A.S. Disponibilidade e Fracionamento de $\mathrm{Cd}, \mathrm{Pb}$, $\mathrm{Cu}$ e $\mathrm{Zn}$ em Função do pH e Tempo de Incubação com o Solo. Ciência e Agrotecnologia, v.32, n.3, p.776-784, 2008. https://doi.org/10.1590/S1413-70542008000300011.

Melo, F.V.; Brown G.G.; Constantino, R.; Louzada, J.N.C.; Lulzão, F.J.; Moraes, J.W., Zanett, R. A importância da mesa e macrofauna do solo na fertilidade e como biondicadores. Boletim Informativo da Sociedade Brasileira de Ciência do Solo, v. 34, n.1, p.39-43, 2009. http://www. alice.cnptia.embrapa.br/alice/handle/doc/428233. 29 Mar. 2018.

Mijangos, I.; Albizu, I.; Epelde, L.; Amezaga, I.; Mendarte, S.; Garbisu, C. Effects of liming on soil properties and plant performance of temperate mountainous grasslands. Journal of Environmental Management, v.91, n.10, p.2066-2074, 2010. https://doi. org/10.1016/j.jenvman.2010.05.011.

Moreira, A; Fageria, N.K. Repartição e remobilização de nutrientes na bananeira. Revista Brasileira de Fruticultura, v. 31, n. 2, p.574581, 2009. https://doi.org/10.1590/S0100-29452009000200036.

Moreira, F.M.S.; Huising, E.J.; Bignell, D.E. A handbook of tropical soil biology: sampling and characterization of below-ground biodiversity. New York: Routledge, 2008. 256p.

Oliveira Filho, L.C.I. et al. Influência dos processos de recuperação do solo após mineração de carvão sobre a mesofauna edáfica em Lauro Müller, Santa Catarina, Brasil. Biotemas, n.27, n.2, p.69-77, 2014. https://doi.org/10.5007/21757925.2014v27n2p69.

Oliveira Filho, L.C.I.; Baretta, D.; Viapiana, C.M.; Santos, J C.P. Mesofauna de solo construído em área de mineração de carvão. Revista de Ciências Agroveterinárias, v. 14, n.1, p.55-64, 2015. http://www.revistas.udesc.br/index.php/agroveterinaria/ article/view/5736. 31 Mar. 2018.

Oliveira Filho, L.C.I.; Klauberg Filho, O.; Baretta, D. Tanaka, C.A.S.; Sousa, P.J. Collembola community structure as a tool to assess land use effects on soil quality. Revista Brasileira de Ciência do Solo, v.40, e0150432, 2016. https://doi.org/10.1590/18069657r bcs20150432.

Pereira, J.C.R.; Moreira, A.; Moraes, L.A.C.; Gasparotto, L. Adubação com boro e zinco para bananeira nas condições edafoclimáticas da região central do estado do Amazonas. Manaus: Embrapa Amazônia Ocidental, 2012. 28p. (Embrapa Amazônia Ocidental. Documentos, 94). http://www.infoteca.cnptia.embrapa.br/ infoteca/handle/doc/942947. 22 Mar. 2018.

Podgaiski, L.R.; Rodrigues, G.G. Spider community responds to litter complexity: insights from a small-scale experiment in an exotic pine stand. Iheringia, Série Zoologia, v.107, e2017007, 2017. https://doi.org/10.1590/1678-4766e2017007.

Pompeo, P.N.; Oliveira Filho, L.C.I.; Klauberg Filho, O.; Mafra, A.L.; Baretta, C.R.D.M.; Baretta, D. Diversidade de Coleoptera (Arthropoda: Insecta) e atributos edáficos em sistemas de uso do solo no Planalto Catarinense. Scientia Agraria, v.17, n.1, p.16-28, 2016. https://doi.org/10.5380/rsa.v17i1.46726. 
Rocha, W.O.; Dorval, A.; Peres Filho, O.; Vaez, C.A.; Ribeiro, E.S. Formigas (Hymenoptera: Formicidae) bioindicadoras de degradação ambiental em Poxoréu, Mato Grosso, Brasil. Floresta e Ambiente, v. 22, n.1, p.88-98, 2015. https://doi. org/10.1590/2179-8087.0049.

Rosa, M.G.; Klauberg Filho, O.; Bartz, M.L.C.; Mafra, A.L.; Sousa, J.P.F.A. de; Baretta, D. Macrofauna edáfica e atributos físicos e químicos em sistemas de uso do solo no Planalto Catarinense. Revista Brasileira de Ciência do Solo. v.39, n.6, n.p.1544-1553, 2015. https://doi.org/10.1590/01000683rbcs20150033.

Ruggiero, M.A.; Gordon, D.P.; Orrell, T.M.; Bailly, N.; Bourgoin, T.; Brusca, R.C.; Cavalier-Smith, T.; Guiry, M.D.; Kirk, P.M. Correction: a higher level classification of all living organisms. Plos One, v.10, n.6, e0130114, 2015. https://doi.org/10.1371/journal. pone.0130114.

Santana, A.S.; Chaves, J.S.; Santana, A.S.; Rodríguez, C.A.; Moraes, E.R. Biomassa microbiana em diferentes sistemas de manejo do solo no sul do estado de Roraima. Revista Brasileira de Ciências da Amazônia, v.6, n.1, p.1-62, 2017. http://www.periodicos.unir. br/index.php/rolimdemoura/article/view/1938. 19 Mar. 2018.

Schiedeck, G.; Schiavon, G.A.; Schwengber, J.E. Sanguessugas em minhocários. Pelotas: Embrapa Clima Temperado, 2009. 3p. (Embrapa Clima Temperado. Comunicado Técnico, 217). http:// www.infoteca.cnptia.embrapa.br/infoteca/handle/doc/747444.

Sial, A.L.; Mcreath, I. Petrologia Ígnea: fundamentos e as ferramentas de estudo. Salvador: Bureau Gráfica e Editora, 1984. 181p.
Silva, P.M.; Carvalho, F.; Dirilgen, T.; Stone, D.; Creamer R.; Bolger, T.; Sousa, J.P. Traits of collembolan life-form indicate land use types and soil properties across an European transect. Applied Soil Ecology, v.97 p.3-11, 2016. https://doi.org/10.1016/j. apsoil.2015.07.018.

Silva, R.F.; Corassa, G.M.; Bertollo, G.M.; Santi, A.L.; Steffen, R.B. Fauna edáfica influenciada pelo uso de culturas e consórcios de cobertura do solo. Pesquisa Agropecuária Tropical, v.43, n. 2, p.130-137, 2013. https://doi.org/10.1590/S198340632013000200001.

Tedesco, M. J.; Gianello, C.; Bissani, C.A.; Bohnen, H.; Volkweiss, S.J. Análise de solo, plantas e outros materiais. 2.ed. Porto Alegre: Universidade Federal do Rio Grande do Sul, 1995. 174p.

Toledo Neto, P.P.T.; Caetano, J.O.; Garcia, L.E.P.; Benites, V.M. Efeito de diferentes fontes de magnésio sobre a produção de biomassa e absorção de cátions pelo milheto. In: Congresso Brasileiro de Ciência do Solo, 35., 2015, Natal-RN. Anais... Natal: SBCS, 2015. https://ainfo.cnptia.embrapa.br/digital/bitstream/ item/138434/1/2015-196.pdf. 19 Mar. 2018.

Ventura, C.R..R; Mello-Patiu, C.A.; Mejdalani, G. Diversidade biológica dos protostomados. v.2. Rio de Janeiro: Fundação CECIERJ, 2010. 239p.

Vibrans, A.C.; Sevegnani, L.; Gasper A.L.; Müller J.J.V.; Reis, M.S. Inventário Florístico Florestal de Santa Catarina: o que você deve saber sobre as florestas de Santa Catarina. Blumenau: FURB, 2015. 19p. 